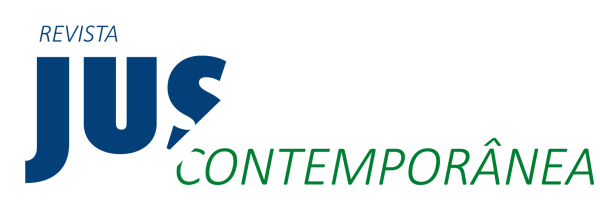

https://doi.org/10.30749/2674-9734.v2n0a318

ARTIGO

\title{
O USO DE INTELIGÊNCIA ARTIFICIAL NOS ESCRITÓRIOS DE ADVOCACIA: ASPECTOS ÉTICOS E PRÁTICOS
}

\section{THE USE OF ARTIFICIAL INTELLIGENCE IN LAW FIRMS: ETHICAL AND PRACTICAL ASPECTS}

Otávio Morato de Andrade ${ }^{1}$

Resumo: A inteligência artificial está mudando o panorama da Justiça no Brasil. Enquanto na esfera pública novos algoritmos computacionais ajudam magistrados e servidores a acelerar o trâmite processual, na advocacia os softwares equipados com IA têm facilitado a organização dos procedimentos e até mesmo a elaboração de petições. Esse artigo investiga o alcance das ferramentas de IA disponíveis na advocacia, bem os desdobramentos práticos e éticos da sua implementação. Para tanto, empreendeu-se uma pesquisa exploratória no campo qualitativo, a partir da qual foi aplicada a técnica indutiva. Primeiramente, apresentamos uma revisão dos conceitos fundamentais pertinentes à inteligência artificial. Em uma segunda etapa, descrevemos as aplicações práticas no atual estado da arte que podem ser implementadas no âmbito da advocacia. Em um terceiro momento, abordamos repercussões práticas e questões éticas atinentes à implementação da IA. Conclui-se que a aplicação de ferramentas de IA na advocacia privada acelera trâmites burocráticos, agrega eficiência à rotina dos escritórios e à marcha processual, permite a canalização de recursos para o atendimento personalizado e gera empregos jurídicos relacionados à criação e gerenciamentos de softwares. A adoção de inteligência artificial na prática jurídica deve ser compatibilizada com questões relativas à transparência, privacidade e segurança de dados.

Palavras-chave: Inteligência artificial; automatização; advocacia.

Abstract: Artificial intelligence is changing the landscape of justice in Brazil. While in the public sphere, new computational algorithms help magistrates and civil servants to speed up the procedural process, in law, software equipped with AI has facilitated the organization of procedures and even the elaboration of petitions. This article investigates the range of AI tools available in law, as well as the practical and ethical consequences of their implementation. Therefore, an exploratory research in the

\footnotetext{
${ }^{1}$ Graduado em Direito (UFMG) e Administração (PUC-MG). Mestre em Direito (UFMG), com bolsa do CNPq. Pós-graduado em Direito Civil pela PUC-MG. Advogado inscrito na OAB/MG. Possui experiência em pesquisa científica, projetos de extensão, monitorias, voluntariados e estágios-docência. É autor de diversas publicações nas áreas de Direito Civil, bioética, tecnologia, inovação, inteligência artificial e economia comportamental. Membro do grupo de estudos SIGA/UFMG, sob coordenação do Prof. Dr. Marco Antônio de Sousa Alves. Ministrou oficinas e palestras no campo do Direito Civil. É parecerista das revistas 'E-Civitas', 'Ambiente: Gestão \& Desenvolvimento' e 'Direito em Debate'.
}

Revista Juscontemporânea, Rio de Janeiro, v.2, p.1-21, set. 2021/ago. 2022 
qualitative field was undertaken, from which the inductive technique was applied. First, we present a review of the fundamental concepts relevant to artificial intelligence. In a second step, we describe practical applications in the current state of the art that can be implemented in the field of law. In a third moment, we address practical repercussions and ethical issues related to AI implementation. It is concluded that the application of AI tools in private law accelerates bureaucratic procedures, adds efficiency to the routine of offices and the process, allows the channeling of resources for personalized service and generates legal jobs related to the creation and management of software. The adoption of artificial intelligence in legal practice must be made compatible with issues related to transparency, privacy and data security.

Keywords: Artificial intelligence; automation; advocacy.

Recebido em: 05/03/2020 Aceito para publicação em: 21/09/2021 


\section{INTRODUÇÃo}

A automação informática já é uma realidade no mundo. A maioria das empresas e órgãos públicos utiliza softwares que executam tarefas tais como o gerenciamento corporativo, controle tributário, fluxo de caixa, cadeia de suprimentos, administração de projetos, transferência eletrônica de fundos, etc. No Direito não é diferente. $\mathrm{O}$ universo jurídico se beneficia há anos desses avanços tecnológicos. No Brasil, o processo eletrônico foi difundido massivamente e se aprimora cada vez mais, ao passo que a consulta jurisprudencial está largamente disponível nos meios digitais. Os órgãos públicos e os advogados também foram beneficiados com as inovações do Sistema de Automação Judiciária (SAJ), que disponibiliza ferramentas de gestão processual, fornecendo recursos como o peticionamento eletrônico, a distribuição randomizada de iniciais e a publicação automática de decisões no DJe.

Para além da automação, as inovações recentes da computação vêm permitindo o desenvolvimento de ferramentas que utilizam uma tecnologia instigante e desafiadora: a inteligência artificial (IA). A IA está dando origem a softwares de arquitetura sofisticada, dotados de algoritmos capazes de desenvolver raciocínios e tomar decisões que emulam o pensamento humano. Mais do que automatizar tarefas repetitivas, os sistemas baseados em IA possuem aptidão para analisar documentos e executar ações com altos índices de acerto, substituindo trabalhadores humanos em diversas tarefas. No âmbito do Direito, essas novas plataformas têm se mostrado capazes de aprimorar pesquisas jurisprudenciais, revisar contratos e elaborar peças jurídicas simples. Tudo isso de forma autônoma, com pouca ou nenhuma interferência humana.

O uso da IA no Direito suscita dúvidas e debates a respeito da nova advocacia que vem surgindo na era pós-digital. Qual será o futuro dos profissionais jurídicos num contexto onde a inteligência artificial estará cada vez mais presente e atuante? Haverá uma "desumanização" da advocacia ou essas transformações possibilitarão uma relação mais sólida entre o cliente e seu patrono? O Direito deixará de ser uma atividade exclusivamente humana e passará às mãos das máquinas inteligentes? 
A partir de um levantamento inicial de algoritmos modelados para escritórios privados, este artigo pretende enfrentar tais questionamentos, examinando a implementação da IA na advocacia sob dois enfoques: consequências práticas e éticas. Para atingir este objetivo, o trabalho foi dividido em três etapas principais. Primeiramente, apresentamos uma prospecção exploratória dos conceitos fundamentais pertinentes à inteligência artificial. Em uma segunda etapa, descrevemos as aplicações práticas no atual estado da arte que podem ser implementadas no âmbito da advocacia. Em um terceiro momento, abordamos repercussões práticas e questões éticas atinentes à implementação de modelos algorítmicos, delineando o surgimento de uma nova advocacia marcada pelo uso da inteligência artificial.

Conclui-se que serão disponibilizadas, a curto e médio prazo, poderosas ferramentas de IA capazes de revolucionar o cotidiano dos escritórios. Se implementado com sucesso, esse conjunto de recursos tem potencial para eliminar várias tarefas cotidianas do advogado, aumentar a eficiência dos escritórios, acelerar a resposta das partes e reduzir a duração dos processos judiciais. Também se vislumbra a criação de empregos jurídicos relacionados ao design e gerenciamento de softwares de IA. Aponta-se, contudo, a existência de problemas cruciais relativos à transparência, privacidade e segurança de dados, de forma que o desenvolvimento de diretrizes éticas é imprescindível para a implementação ostensiva da IA no território jurídico.

\section{INTELIGÊNCIA ARTIFICIAL}

A inteligência artificial (IA) é descrita por John Haugeland (1985, p. 15) como "o novo e empolgante esforço para fazer computadores pensar (...) máquinas com mentes, no total e sentido literal". Na concepção de Robert Schalkoff (1990), trata-se de "um campo de estudo que procura explicar e emular o comportamento inteligente em termos de processos computacionais". Para Stuart Russel \& Peter Norvig (2020) a inteligência artificial é a capacidade da máquina de interpretar dados de forma 
racional e humana, tomando decisões autônomas com base em padrões preexistentes. Já John Simons (2016, p. 5) preleciona que é a ciência de ensinar computadores a "aprender, raciocinar, perceber, inferir, comunicar e tomar decisões como os humanos".

Mas como um sistema artificial é capaz de pensar de forma inteligente? De acordo com o Grupo de Experts em IA da União Europeia (2019, p. 1), o software "percebe o ambiente em que está imerso através de sensores, coletando e interpretando dados, processando as informações sobre os dados recebidos para decidir qual é a melhor ação". Esses sistemas de IA também podem adaptar seu comportamento analisando como o ambiente foi afetado por suas ações anteriores. Luiz Fux $(2019$, p. 2) entende que o conceito de IA é indissociável de um mecanismo fundamental para a sua existência: o método de aprendizado de máquina, ou machine learning. Harry Surden (2014, p. 89) fornece uma definição precisa sobre essa técnica:

O machine learning consiste na capacidade de os sistemas se adaptarem a novas circunstâncias e extrapolar padrões previamente estabelecidos, isto é, aprendendo com os dados já conhecidos e, assim, produzindo novas informações capazes de subsidiar tomadas de decisão futuras

No machine learning, o computador é desenvolvido para "se autoprogramar" com base em sua própria experiência. Ele reúne dados, interpreta essas informações e toma decisões diferenciadas, trabalhando com padrões cognitivos similares aos usados por humanos (ARENS, 2017). Além das adaptações realizadas pelo próprio sistema com base em sua experiência prévia, o machine learning pode se dar através da intervenção humana. Neste sentido, os desenvolvedores podem reeditar o código do software, fazendo ajustes e correções até que o computador passe a executar a tarefa com grau aceitável de acuidade (MILLER, 2019, p. 3).

A ideia de se utilizar os computadores na automatização de rotinas jurídicas surgiu com as pesquisas de Loevinger no final dos anos 40 , mas foi na década de 60 que se iniciaram os primeiros estudos práticos sobre a aplicação de algoritmos no Direito. Nas décadas de 70 e 80 , como resultado destas pesquisas, surgiram os 
primeiros sistemas de automação jurídica, notadamente os TAXMAN $^{2}$ e o HYPO ${ }^{3}$. Após anos de descrédito e avanços tímidos, a inteligência artificial ressurgiu com grande força a partir dos anos 2000, a reboque das grandes empresas de tecnologia que emergiram com a popularização da internet. A partir de 2010, os consequentes avanços científicos possibilitaram a introdução da inteligência artificial em softwares jurídicos como o ROSS e o LawGeex, sistemas que, como veremos adiante, são capazes de analisar contratos e emitir pareceres jurídicos com enorme velocidade e precisão.

Luiz Fux (2019, p. 3) relata que a IBM definiu seis categorias de potenciais aplicações da inteligência artificial ao Direito, a saber: previsão de resultados de conflitos judiciais, elaboração de peças jurídicas; revisão de contratos; identificação de padrões em decisões judiciais; rastreamento de propriedade intelectual e mecanização do faturamento de honorários. Nos tópicos a seguir, veremos como algumas dessas aplicações podem ser incorporadas no contexto dos escritórios de advocacia.

\section{AUTOMAÇÃO E INTELIGÊNCIA ARTIFICIAL NA ADVOCACIA}

De acordo com o Relatório Justiça em Números, o Poder Judiciário tem cerca de 75 milhões de processos judiciais em tramitação (CNJ, 2021). Além disso, Ordem dos Advogados do Brasil ( $O A B$ ) estima que a advocacia já soma mais de um milhão de profissionais em atuação (MARTINS, 2019). O país é, portanto, um mercado com grande potencial para o desenvolvimento de tecnologias que facilitem a rotina jurídica. Na esteira dessa tendência estão as empresas de Lawtech e Legaltech ${ }^{4}$. De

\footnotetext{
2 TAXMAN-I e TAXMAN-II foram softwares desenvolvidos na década de 1970, na Universidade de Rutgers (E.U.A) com o intuito de analisar taxações das reorganizações das sociedades por ações, identificando com base no caso concreto e nas leis, quais operações estariam isentas de taxação (MAGALHÃES, 2004, p. 340)

${ }^{3}$ HYPO é um sistema projetado em 1987 para analisar casos de direito contratual estadunidense utilizando o Raciocínio Baseado em Casos. Diante de um caso apresentado pelo usuário, construía uma apropriada argumentação com base em exemplos e precedentes (MAGALHÃES, 2004, p. 344)

${ }^{4}$ Para HEYMANN (2018, p. 4), há divergência se Law Tech e Legal Tech são sinônimos. Apesar dos profissionais da área, majoritariamente, entenderem ambos os termos como sinônimos, alguns especialistas sugerem o uso do termo "Lawtech" para empresas com foco nas leis, enquanto
}

Revista Juscontemporânea, Rio de Janeiro, v.2, p.1-21, set. 2021/ago. 2022 
acordo com Erik Nybo (2017) "Lawtechs ou Legaltechs, ambos nomes utilizados para as empresas do segmento, são startups focadas em criar produtos ou serviços para o mercado jurídico."

O uso da inteligência artificial na advocacia tem atraído muita atenção nos últimos anos. Atualmente, a Associação Brasileira de Lawtechs e Legaltechs (AB2L) registra mais de cinquenta startups no mercado legal no país. Há dois anos atrás existiam apenas vinte empresas do gênero. De acordo com Samia Frantz (2019), a AB2L divide as Lawtechs brasileiras em onze categorias, a saber: i) analytics e jurimetria5; ii) automação e gestão de documentos; iii) compliance; iv) conteúdo jurídico, educação e consultoria, v) extração e monitoramento de dados públicos; vi) gestão jurídica; vii) inteligência artificial; viii) redes de profissionais; ix) regtechs ${ }^{6} ; \mathrm{x}$ ) resolução de conflitos online e xi) taxtech? .

Dentre essa extensa gama de aplicações, nos interessa, em especial, o uso da inteligência artificial no cotidiano da advocacia. Nos tópicos a seguir, demonstraremos exemplos de softwares que utilizam alta tecnologia para solucionar problemas jurídicos. Embora também executem tarefas tradicionais de automação, todos estes sistemas possuem um diferencial importante: eles são equipados com algoritmos de inteligência artificial, que permitem o processamento de informações, a interação fluida com o usuário e o aperfeiçoamento constante do software através do aprendizado de máquina.

\footnotetext{
"Legaltech" se encaixaria melhor para as empresas que lidam com os diversos procedimentos da área legal.

${ }^{5}$ Analytics refere-se à técnica de se utilizar grande quantidade de dados e raciocínio estatístico para dar seguimento a um processo de tomada de decisão mais eficiente (ZIMMERMANN, 2018). Já a Jurimetria se refere à aplicação, na área do Direito, dessas técnicas quantitativas comuns à estatística. Trata-se de uma disciplina que ajuda os legisladores e operadores do Direito a criar instituições sociais e políticas públicas mais justas e eficientes (FERRAZ, 2018).

${ }^{6}$ Regtechs são empresas que oferecem soluções tecnológicas capazes de resolver problemas gerados pelas exigências de regulamentação. É o caso, por exemplo, do SigaLei. Essa Lawtech analisa dados de diversas fontes para facilitar o monitoramento legislativo automático e influenciar o poder legislativo em todas as esferas (FRANTZ, 2019).

7 Taxtechs são empresas que desenvolvem plataformas e soluções tecnológicas voltadas especificamente para questões tributárias. Um exemplo é a Busca Legal, que oferece acesso especializado a jurisprudências e conteúdos diversos e consulta à tributação de determinado produto (FRANTZ, 2019).
} 


\section{1 "ROSS": tecnologia da IBM à serviço de pesquisas jurídicas confiáveis}

Desde 2014, pesquisadores da Universidade de Toronto, no Canadá, vêm desenvolvendo o software ROSS (BECKER \& LAMEIRÃO, 2017). A plataforma é baseada em tecnologia de inteligência artificial da $\mathrm{IBM}^{8}$, e tem por objetivo oferecer pesquisas detalhadas e confiáveis aos advogados na busca de argumentos para suas ações, através da comparação de jurisprudência, doutrina e normas legais.

O ROSS pode processar, em apenas um segundo, quinhentos gigabytes de dados, o equivalente a um milhão de livros. Isso permite que ele arquive toda a legislação do país, jurisprudências, precedentes, citações e qualquer outra fonte de informação jurídica. Além disso, pode atualizar seu conteúdo vinte e quatro horas por dia, todos os dias, e alertar o advogado sobre informações recentes que afetem um caso em que está trabalhando (GUERRA, 2017). De acordo com Michal Addady (2016), a plataforma também é capaz de extrair conclusões ao analisar a literatura jurídica, selecionar informações relevantes para um caso específico, formular hipóteses, gerar respostas sustentadas por referências e interagir com o usuário.

A interface do sistema é simples e intuitiva: o advogado faz uma pergunta e o robô soluciona a questão, citando precedentes jurídicos, leis relacionadas e até um percentual de confiabilidade da resposta fornecida. O sistema também é capaz de pesquisar em outros idiomas e alertar o advogado para novas mudanças de entendimento e tendências jurisprudenciais (idem, 2016). Em 2016, a Baker \& Hostetler, uma das maiores bancas de advocacia dos EUA, "contratou" o ROSS para a automatização de tarefas jurídicas na área de falências. O software foi instalado nos computadores dos escritórios da firma, e já está operando como fonte de pesquisas para cinquenta advogados da divisão de falências (MELO, 2016).

Segundo Luiz Fux (2019), o ROSS possui um subsistema ainda mais automatizado, chamado EVA, que funciona especificamente para a análise de peças processuais. No EVA, o usuário pode inserir a petição inicial ou contestação

\footnotetext{
${ }^{8}$ O Ross utiliza como base o sistema de inteligência artificial Watson, desenvolvido pela IBM. Pode-se dizer, portanto, que o Ross é uma variante jurídica do Watson (SILLS, 2016)
} 
apresentada pelo advogado da outra parte, deixando que a máquina pesquise a jurisprudência citada, identifique as partes do texto mais relevantes, busque jurisprudência atualizada sobre essas informações e apresente-as de forma concisa.

\section{2 "LawGeex" e "KiraSystems": análise de contratos e identificação de cláusulas defeituosas ou indesejáveis}

A LawGeex é uma empresa israelense fundada em 2014, que desenvolve tecnologia automatizada de revisão de contratos. 0 sistema visa reduzir os recursos humanos e financeiros com a análise e aprovação de minutas, e foi projetado para responder à seguinte pergunta: "Posso assinar isso?". Para solucionar a questão, o robô utiliza algoritmos computacionais que examinam as cláusulas, verificam a sua legalidade com base no ordenamento jurídico e investigam se o contrato cumpre critérios preestabelecidos pelo usuário (O'HEAR, 2017). Caso seja encontrada uma contradição jurídica ou um dispositivo contratual que possa prejudicar os interesses do usuário, o sistema envia um alerta ao advogado para que ele revise a cláusula defeituosa ou indesejada.

Em um estudo divulgado pela LawGeex (2018), advogados americanos com décadas de experiência em direito societário e revisão de contratos foram confrontados com um computador para detectar problemas em cinco contratos NDA (Non-Disclosure Agreement) 9 . Os profissionais humanos competiram contra um sistema LawGeex, que foi desenvolvido por três anos e treinado através de machine learning com base em dezenas de milhares de contratos. Após extensos testes, o sistema alcançou uma média de $94 \%$ de acertos na identificação de cláusulas problemáticas, enquanto os advogados atingiram um índice de $85 \%$. Em média, foram necessários 92 minutos para que os profissionais humanos analisassem todos os cinco NDA's propostos. O advogado que consumiu mais tempo gastou 156

\footnotetext{
9 Um acordo de não-divulgação (NDA, Non-Disclosure Agreement) é um contrato legal de confidencialidade, através do qual as partes concordam em não divulgar determinadas informações.
}

Revista Juscontemporânea, Rio de Janeiro, v.2, p.1-21, set. 2021/ago. 2022 
minutos na análise, enquanto o profissional mais rápido fez a revisão em 51 minutos. Por sua vez, o computador concluiu a tarefa em apenas 26 segundos.

De forma semelhante, a empresa canadense KiraSystems, criada em $2011^{10}$, desenvolve softwares para auxiliar advogados na análise de cláusulas contratuais, sobretudo em fusões e aquisições, comparando as informações presentes nos contratos com os esclarecimentos apresentados à autoridade antitruste responsável por supervisionar e aprovar as operações (FUX, 2019).

\section{3 "LexMachina": avaliação de patentes e simulação de riscos}

Fundada em 2010 (BLOOMBERG, 2017), a LexMachina é fruto de pesquisas desenvolvidas nas faculdades de Direito e de Ciência da Computação da Universidade de Stanford. O nome da empresa é uma expressão latina que significa "máquina do direito" (SCHUBARTH, 2013). A empresa oferece um conjunto de aplicativos que possibilitam uma gama de ferramentas aos advogados, entre as quais: i) avaliar o grau de ameaça representada por um novo caso, simulando riscos de prejuízos financeiros e sanções judiciais; ii) permitir a elaboração de peças jurídicas com argumentação robusta e confiável e iii) emitir relatórios sobre patentes e avaliar disputas de propriedade intelectual.

De 2000 a 2013, o LexMachina compilou dados de 147.000 casos de propriedade intelectual, montando uma extensa base de dados de patentes, direitos autorais, marcas registradas e casos antitruste. 0 sistema também é capaz de extrair publicações do Departamento de Marcas e Patentes e das cortes judiciais estadunidenses, disponibilizando-os para pesquisa dentro da plataforma. A mineração dessas informações permite que os advogados acompanhem tendências processuais de tribunais específicos, históricos de advogados e das partes adversárias, além de estimar prováveis custos e desdobramentos do litígio (HOGE, 2013).

\footnotetext{
${ }^{10}$ Lawgeek. Startup map. KiraSystems. Disponível:

https://www.legalgeek.co/startup-map-v1/kirasystems/
}

Revista Juscontemporânea, Rio de Janeiro, v.2, p.1-21, set. 2021/ago. 2022 


\subsection{Chatbots e o "DoNotPay": assistente jurídico via chat}

Chatbots (em inglês "chat" = conversa; "bot" = robô) são softwares que tentam simular um ser humano na conversação com as pessoas. $O$ objetivo desses programas é responder perguntas de tal forma que o usuário tenha a impressão de estar conversando com outra pessoa e não com um programa de computador. Depois que o usuário formula um questionamento por mensagem de texto, o programa consulta seu banco de dados ou a internet, e em seguida fornece uma resposta em linguagem humana e acessível (ELOVIC, 2017). Desta forma, o software constrói respostas automatizadas com base em palavras-chave contidas na pergunta inserida. Os chatbots também utilizam aprendizado de máquina para aumentar o grau de precisão das respostas e dar mais naturalidade às conversas, tornando os chats com mais parecidos com as interações humanas.

O DoNotPay, ou numa tradução livre, "Não pague a sua multa", é um aplicativo disponível na AppleStore, que utiliza um sofisticado chatbot para responder consumidores insatisfeitos com serviços de outras empresas ou órgãos públicos. Quando foi criado, em 2015, a ideia inicial era que o DoNotPay examinasse multas de trânsito inseridas pelo usuário, formulando dicas personalizadas para que o motorista escolhesse os melhores recursos administrativos ou jurídicos para contestar a sanção. De acordo com o The Guardian (2016), o aplicativo solucionou 160.000 casos em menos de dois anos, livrando usuários de mais de 4 milhões de dólares em multas.

Com o tempo, a abrangência e complexidade do sistema aumentaram, e o aplicativo passou a oferecer "assistência jurídica" a pessoas com as mais diversas reclamações sobre órgãos públicos ou empresas, tais como: problemas com aplicativos de entrega, desentendimentos com companhias aéreas, contestação de taxas bancárias consideradas abusivas, etc.

Ao receber a reclamação do cliente, o programa faz uma série de perguntas específicas sobre a situação para, então, orientar o usuário sobre seus direitos e 
formular uma lista de documentos que autor precisaria para dar entrada no processo. O DoNotPay também fornece orientações sobre os trâmites processuais, como audiências e estimativas de prazo, caso o autor decida processar a empresa (BOYCE, 2016).

\section{O SURGIMENTO DE UMA NOVA ADVOCACIA}

\subsection{A prática jurídica transformada}

As tendências e ferramentas demonstradas no capítulo anterior indicam que a inteligência artificial tem um enorme potencial para transformar a advocacia. No futuro, o uso sistêmico e massificado das ferramentas computacionais provavelmente mudará o cotidiano da maioria dos profissionais jurídicos.

Os sistemas existentes até o momento evidenciam que as máquinas dotadas de IA já podem, com considerável grau de confiança, realizar pesquisas e identificar inconsistências em documentos. Por si só, esses avanços podem contribuir para que o advogado produza peças jurídicas mais persuasivas e confiáveis. As experiências relatadas também apontam para uma redução no tempo e nos recursos dispensados ao trabalho técnico em cada processo.

Essa economia de tempo e de dinheiro através da utilização da IA também tem sido identificada em experiências no setor judiciário, como registrou recentemente o presidente do Supremo Tribunal Federal, Ministro Dias Toffoli (2019):

O trabalho que custaria ao servidor de um tribunal entre 40 minutos e uma hora para fazer, o software faz em cinco segundos. Nossa ideia é replicar junto aos Tribunais Regionais Federais (TRFs), aos Tribunais de Justiça, aos Tribunais Regionais do Trabalho, enfim, trata-se de uma ferramenta para toda a magistratura 
Neste sentido, a propagação dessas novas tecnologias pelos Tribunai $\mathrm{s}^{11}$, pode contribuir para aumentar a produtividade do Judiciário, melhorando a qualidade e a eficiência da prestação jurisdicional (ANDRADE, 2019). Por outro lado, é possível que o computador ainda esteja longe de sentenciar litígios ou elaborar peças jurídicas completas. Isso porque essas tarefas têm alto grau de complexidade, demandando, ademais, refinadas habilidades de ponderação que ainda não estão ao alcance dos softwares (BELTRÃO FILHO \& CRUZ, 2019). Desta forma, embora possam realizar atividades mecânicas e substituir o trabalho manual repetitivo, os softwares de inteligência artificial dificilmente realizarão, com perfeição, o trabalho de um bom advogado na redação de peças jurídicas e na análise e elaboração de estratégia em casos mais complexos.

Além disso, nos parece, a princípio, ser impossível substituir o papel de apoio e aconselhamento dado a um cliente. O lado humano que o suporte do advogado fornece é insubstituível, pois a advocacia requer interação interpessoal, criatividade, processamento de linguagem, compreensão de como funciona a sociedade, sensibilidade e experiência. Em curto e médio prazo, o domínio pleno e refinado de todas essas características dificilmente será atingido pelo computador (ANDRADE, 2021). Com base nessas considerações, podemos elencar quatro perspectivas para $O$ futuro da advocacia:

1) Algumas tarefas do advogado poderão ser eliminadas, notadamente aquelas que envolvem organização de documentos e pesquisa de jurisprudência. Isso se dará porque os sistemas de inteligência artificial possuem uma enorme capacidade de varredura de textos e de rastreamento de informações. Como visto, um computador consegue identificar, com notável agilidade e precisão, as informações necessárias em bases de dados extensas. Os sistemas de IA também

\footnotetext{
${ }^{11}$ O Poder Judiciário brasileiro já utiliza alguns softwares de inteligência artificial para agilizar tarefas processuais. Alguns exemplos: O STF desenvolveu, em 2018, o robô Victor, que analisa automaticamente requisitos de admissibilidade em casos de repercussão geral. O STJ implantou, a partir de 2019, o Corpus927, que ajuda na triagem de processos relacionados ao artigo 927 do CPC. Outras cortes judiciais como o TJPE, TJRO e TJRN também já estão utilizando a inteligência artificial para triar processos, verificar admissibilidade de petições e executar bloqueios como BACENJUD e RENADJUD de forma automatizada (ANDRADE, 2019).
} 
são hábeis em organizar a disposição dessas informações para entregá-las ao usuário de forma simples e intuitiva.

2) Outros empregos serão criados, sobretudo na área de concepção, manutenção e gestão destas ferramentas automatizadas. As Lawtechs já dão uma amostra deste novo mercado de trabalho. Embora os algoritmos computacionais sejam programados por engenheiros e técnicos de tecnologia da informação, os profissionais jurídicos terão importância fundamental no desenvolvimento e na revisão dos recursos de IA no Direito. Tendo em vista a demanda futura por estes novos profissionais, o professor de Stanford Leonard Susskind (2010) chama a atenção para o advento de uma nova profissão, a dos "engenheiros legais":

Precisamos de uma geração de advogados capazes de desenhar, desenvolver, entregar e manter os sistemas que substituirão as velhas formas de trabalhar. Precisamos de uma geração de engenheiros legais.

3) A IA pode aumentar o rendimento e a produtividade dos escritórios, na medida em que fornece pesquisas e diagnósticos automatizados, com grau cada vez maior de precisão e confiabilidade. $\mathrm{O}$ uso dessas ferramentas pode tornar as tarefas mais rápidas e financeiramente menos dispendiosas. Desta forma, o advogado terá mais tempo para dedicar-se a outras atividades, como o autoaperfeiçoamento e a defesa de novas causas, além de ter maior disponibilidade para fornecer um tratamento diferenciado e personalizado a seus clientes. Este "toque humano" é importantíssimo e dificilmente será substituído pelas máquinas.

4) A aplicação sistêmica de novas tecnologias pelos Tribunais pode contribuir para reduzir a morosidade da Justiça, na medida em que auxilia magistrados e servidores a acelerar o trâmite processual através de recursos automatizados. Numa perspectiva esperançosa, é possível que o judiciário nacional consiga obter, através da aplicação da IA, a redução do passivo de ações que afoga o sistema e dificulta o acesso à uma prestação jurisdicional efetiva.

\subsection{Desdobramentos éticos}


O uso da computação cognitiva, como toda revolução tecnológica, oferecerá certos riscos e dilemas, que devem ser tratados de forma adequada e proporcional, de forma a resguardar a ética e os direitos fundamentais. Na medida em que o Poder público e os escritórios de advocacia implantam inovações de inteligência artificial, surge a preocupação em harmonizar essas novas tecnologias com os princípios da sociedade.

Entre as inúmeras implicações da inteligência artificial descritas na doutrina, podemos elencar: a) presença de vieses cognitivos nos algoritmos de IA, que eventualmente produzem resultados discriminatórios ${ }^{12}$ ou pouco transparentes ${ }^{13} ; b$ ) as ameaças à privacidade, na medida em que os robôs podem acessar e interpretar informações pessoais do indivíduo ${ }^{14}$; c) a possível substituição dos humanos pelas máquinas no ambiente de trabalho (ACEMOGLU \& RESTREPO, 2018; UNGER, 2018, p. 68); d) o problema da responsabilização no caso do cometimento de ilícito por uma máquina (2019, p. 5); e) o uso militar de armamentos robóticos altamente destrutivos ${ }^{15}$; f) a hipótese das consequências não-intencionais, segundo a qual os sistemas computacionais sofreriam uma "explosão de inteligência" (HELM \& MUEHLHAUSER, 2012), agregando um nível de complexidade e sofisticação incontrolável pelos seres humanos (ANDRADE, 2019, p. 15).

Diante dessa profusão de possíveis impactos e desdobramentos, examinar a IA à luz da ética e dos direitos fundamentais é uma oportunidade de moldar seu desenvolvimento, garantindo que essas novas tecnologias computacionais se desenvolvam de maneira segura, oferecendo um ambiente de operação confiável para seus próprios usuários. Um exemplo é o incentivo à inteligência artificial

\footnotetext{
${ }^{12}$ Segundo Dierle José Coelho Nunes (p. 6), um robô que avalia o risco de reincidência de criminosos nos Estados Unidos passou a classificar erroneamente os acusados negros como prováveis reincidentes, e os acusados brancos como indivíduos de baixo risco.

13 Dierle José Coelho Nunes (p. 8) relata que "(...) os algoritmos utilizados nas ferramentas de inteligência artificial são obscuros para a maior parte da população - algumas vezes até para seus programadores (...) - o que os torna, de certa forma, inatacáveis."

${ }^{14}$ Um relatório do Governo Norueguês, "Artificial intelligence and privacy" (2018), descreve os riscos e preocupações governamentais relacionados ao armazenamento e manipulação de dados pessoais por máquinas. Disponível em: https://www.datatilsynet.no/globalassets/global/english/ai-and-privacy.pdf ${ }^{15}$ O Professor de Oxford, Nick Bostrom afirma que a inteligência artificial gera os chamados riscos existenciais: "ameaças que podem causar nossa extinção ou destruir o potencial da vida inteligente que origina a Terra" (tradução nossa). Disponível em https://nickbostrom.com/existential/risks.html
}

Revista Juscontemporânea, Rio de Janeiro, v.2, p.1-21, set. 2021/ago. 2022 
explicável (XAI), que consiste no desenvolvimento de funcionalidades "autoexplicativas", para que algoritmos consigam demonstrar, a um humano médio, as suas etapas e métodos de raciocínio para se chegar a determinada decisão (NUNES \& ANDRADE, 2021; ALVES \& ANDRADE, 2021). Isso porque o ser humano não pode ficar refém de algoritmos "caixa-preta", cujo raciocínio, altamente complexo e ininteligível, é impossível acessar ou entender - especialmente quando o sistema de IA é utilizado em áreas sensíveis, como a tomada de decisões judiciais, por exemplo.

Considerando a lição de Norberto Bobbio, segundo o qual valores e princípios de uma civilização repousam na ética e os direitos humanos são a consagração normativa das conquistas históricas do cidadão (BOBBIO, 1998, p. 363), entendemos que é essencial harmonizar o uso da inteligência artificial com esses preceitos basilares da sociedade. Afinal, se o uso da inteligência artificial tem o intuito de aperfeiçoar o bem-estar e a liberdade, seu grande beneficiário é, pois, o próprio indivíduo, razão pela qual a aplicação da IA jamais poderia se distanciar dos princípios éticos de uma sociedade ou confrontar as garantias fundamentais franqueadas pelo Estado Democrático de Direito (ANDRADE, 2019).

Neste sentido, a União Europeia formulou, muito recentemente, as "Diretrizes Éticas para a Inteligência Artificial Confiável" (UNIÃO EUROPEIA, 2019b). O documento estabelece normas para o desenvolvimento de ferramentas de inteligência artificial, justamente com base nos erros, riscos e impactos negativos que o raciocínio automatizado pode produzir (FRAZÃO, 2019). Essas diretrizes estão apoiadas em dois sustentáculos básicos: direitos fundamentais (dignidade humana, liberdade do indivíduo, igualdade, solidariedade, não-discriminação, respeito aos cidadãos e ao Estado de Democrático Direito) e os princípios éticos do respeito à autonomia humana, prevenção de danos, justiça e explicabilidade. Partindo dessas premissas éticas, o guia também emitiu sete diretrizes técnicas a serem seguidas por empresas e governos na concepção e aplicação da IA. São elas: i) fiscalização; ii) segurança técnica; iii) privacidade e governança de dados; iv) transparência; v) 
diversidade, não-discriminação e equidade; vi) bem-estar social e ambiental; vii) responsabilização.

Tal como a União Europeia, outros países devem se preocupar em estabelecer critérios para o emprego de inteligência artificial. Estes novos marcos regulatórios devem oferecer normas preventivas e estipular soluções para os impactos gerados pelo o avanço da computação cognitiva.

\section{CONCLUSÃO}

A crescente indústria de tecnologia jurídica está colocando um conjunto cada vez maior de ferramentas de Inteligência Artificial à disposição dos escritórios de advocacia. Atualmente, a maioria desses recursos está direcionada para a revisão de contratos, análise jurisprudencial e pesquisa de documentos.

Neste contexto, o uso de robôs pode transformar a vida jurídica e o cotidiano dos escritórios, suscitando novas perspectivas para a advocacia, como vimos nos capítulos anteriores: 1) eliminação de algumas tarefas do advogado, sobretudo as que envolvem organização de documentos e pesquisas jurisprudenciais; 2) criação de empregos relacionados à concepção e gerenciamento de ferramentas automatizadas; 3) aumento da eficiência dos escritórios, com economia de tempo e recursos financeiros, que poderão ser reinvestidos pelo advogado de várias formas; 4) redução da morosidade na Justiça, ensejando maior eficácia na prestação jurisdicional e melhoria no atendimento dos advogados pela estrutura dos órgãos judiciários.

Vimos também que os softwares de IA dificilmente substituirão, com plenitude, o trabalho de um bom advogado na redação de peças jurídicas sofisticadas e no raciocínio estratégico em casos mais complexos, uma vez que a IA ainda está longe de adquirir capacidade de dimensionamento ético e ponderação de valores para mensurar as especificidades de cada caso em concreto.

Por derradeiro, pontuou-se que, como as demais revoluções tecnológicas, a inteligência artificial oferece novos riscos e dilemas morais. Esses desafios, que 
incluem questões de transparência, privacidade e segurança de dados, devem ser tratados com respeito às garantias fundamentais resguardadas pelo Estado Democrático de Direito e à luz dos valores éticos que permeiam a sociedade.

\section{REFERÊNCIAS}

ACEMOGLU, Daron \& RESTREPO Pascual. Artificial Intelligence, Automation and Work. NBER Working Paper No. 24196 Jan 2018.

ADDADY, Michal. Meet Ross, the World's First Robot Lawyer. Rev Fortune. Mai 2016. [acesso em 15/06/2019] Disponível: http://fortune.com/2016/05/12/robot-lawyer/

ALVES, Marco Antônio Sousa; ANDRADE, Otávio Morato de. Da "caixa-preta" à "caixa de vidro": o uso da Explainable Artificial Intelligence (XAI) para reduzir a opacidade e enfrentar o enviesamento em modelos algorítmicos. Revista de Direito Público v. 18, n. 100. No prelo.

ANDRADE, Otávio Morato de. Utilizando inteligência artificial para combater a morosidade processual e democratizar o acesso ao judiciário. Revista Duc in Altum. No prelo. Recife, 2021.

ANDRADE, Otávio Morato de. "Doutor Robô"? A substituição dos advogados pelas máquinas e outras considerações sobre o Direito na era pós-digital in Transformações nas organizações e na prática jurídica. Alexandre Pacheco da Silva, Emerson Ribeiro Fabiani e Marina Feferbaum (Org.) - São Paulo: Fundação Getúlio Vargas, 2021, p. 221-239.

ARENS, Bob. Cognitive computing: Under the hood. Thomson Reuters. Jan 2017. Disponível em

https://blogs.thomsonreuters.com/answerson/cognitive-computing-hood/

BECKER, Daniel \& LAMEIRÃO, Pedro. Better call ROSS. Direito da Inteligência Artificial. Disponível:

https://direitodainteligenciaartificial.com/2017/07/05/better-call-ross/\# ftn5

BELTRÃO FILHO, João Alfredo \& CRUZ, Jaqueline. O uso da inteligência artificial na análise de processos no Judiciário como instrumento de concretização da eficiência processual. Jota. Mai 2019. Disponível:

https://www.jota.info/opiniao-e-analise/colunas/coluna-cpc-nos-tribunais/uso-da-intel igencia-artificial-na-analise-de-processos-como-instrumento-de-eficiencia-31052019 
BLOOMBERG. Company Overview of Lex Machina, Inc. 2017. Disponível:

https://www.bloomberg.com/research/stocks/private/snapshot.asp?privcapId=11908 $\underline{2530}$

BOBBIO, Norberto. Dicionário de Política. Vol. I. 11a ed. Editora UNB. 1998

BOYCE, Lee. Plucky student entrepreneur who created parking ticket appeal website now launches robot to give Britons free legal help. Jornal Daily Mail. Jan 2016. Disponível:

https://www.dailymail.co.uk/money/news/article-3394093/Joshua-Browder-created-D oNotPay-launches-robot-Britons-free-legal-help.html?ITO=1490\&ns mchannel=rss\&n $\underline{\text { s campaign }=1490}$

CONSELHO NACIONAL DE JUSTIÇA (CNJ). Relatório Justiça em Números 2021. Disponível:

https://www.cnj.jus.br/wp-content/uploads/2021/11/relatorio-justica-em-numeros20 21-221121.pdf

ELOVIC. Assaf. Chatbots - The Beginners Guide. Chatbots Magazine. Ago 2017. Disponível:

https://chatbotsmagazine.com/chatbots-the-beginners-guide-618e72599b55

FRANTZ, Sâmia. Lawtech e legaltech: startups jurídicas e a revolução na advocacia. SAJ Adv. Fev 2019. Disponível:

https://blog.sajadv.com.br/lawtech-e-legaltech/

FRAZÃO, Ana. Quais devem ser os parâmetros éticos e jurídicos para a utilização da IA? Rev. Jota. Disponível:

https://www.jota.info/opiniao-e-analise/colunas/constituicao-empresa-e-mercado/qu ais-devem-ser-os-parametros-eticos-e-juridicos-para-a-utilizacao-da-ia-24042019

FUX, Luiz. Palestra sobre Inteligência artificial. Conjur. Fev 2019. Disponível: https://www.conjur.com.br/dl/palestra-fux-inteligencia-artificial.pdf

GUERRA, Gustavo Rabay. A invasão das Lawtechs e o avanço exponencial das novas tecnologias no setor de serviços legais. Medium. Set 2017. Disponível: https://medium.com/@gustavorabay/a-advocacia-na-era-p\%C3\%B3s-digital-a-invas \%C3\%A3o-das-lawtechs-e-o-avan\%C3\%A7o-exponencial-das-novas-tecnologias-e09 eb59f78da

HAUGELAND, John. Artificial Intelligence: The Very Idea. Cambridge: MIT Press, Massachusetts, 1985.

HELM, Louie \& MUEHLHAUSER, Luke. Intelligence Explosion and Machine Ethics. 2012. 
HOGE, Patrick. Lex Machina: Lex Machina: 'Moneyball' meets patent lawsuits. Setembro de 2013. Disponível:

https://www.bizjournals.com/sanfrancisco/blog/2013/09/lex-machina-mines-lawsuit-d ata.html?page $=$ all

LAWGEEK. Startup map. KiraSystems. Disponível:

https://www.legalgeek.co/startup-map-v1/kirasystems/

LAWGEEX. Comparing the Performance of Artificial Intelligence to Human Lawyers in the Review of Standard Business Contracts. Fev 2018. Disponível: http://ai.lawgeex.com/rs/345-WGV-842/images/LawGeex\%20eBook\%20Al\%20vs\%2 0Lawyers\%202018.pdf

MARTINS, Kamila Mendes. Brasil chega a 1 milhão de advogados. Disponível: https://www.gazetadopovo.com.br/vida-publica/justica-e-direito/brasil-chega-a-1-mil hao-de-advogados-636e8p084e82q2vq2du4excr1/

MELO, João Osório. Escritório de advocacia estreia primeiro "robô-advogado" nos EUA. Rev. Conjur, 2017. Disponível:

https://www.conjur.com.br/2016-mai-16/escritorio-advocacia-estreia-primeiro-robo-a dvogado-eua

MILLER, Sterling. Artificial intelligence and its impact on legal technology: to boldly go where no legal department has gone before. Thomson Reuters. Disponível: https://static.legalsolutions.thomsonreuters.com/static/pdf/S045 388_1_Final.pdf

NUNES, Dierle José Coelho; ANDRADE, Otávio Morato de. A explicabilidade das tecnologias de inteligência artificial como novo conteúdo de um devido processo legal tecnológico. Revista de Direito Público v. 18, n. 100. No prelo.

O'HEAR, Steve. LawGeex raises \$12M for its AI-powered contract review technology. Rev TechCrunch, 2017. Disponível em:

https://techcrunch.com/2018/04/17/lawgeex-raises-12m-for-its-ai-powered-contract-r eview-technology/

RUSSEL, Stuart. \& NORVIG, Peter. Artificial Intelligence: A Modern Approach. Pearson, 2020.

SCHALKOFF, Robert. Artificial Intelligence: An Engineering Approach. Ed. McGraw-Hill, 1990.

SCHUBARTH Cromwell. Law Big Data startup Lex Machina raises \$4.8M. Silicon Valley Business Journal. Mai 2013. Disponível:

https://www.bizjournals.com/sanjose/news/2013/05/01/law-big-data-startup-lex-mac hina.html?page=all 
SIMONS, John. Tomorrow's Business Leaders Learn How to Work with A.I. The Wall Street Journal. Nov. 2016. Disponível:

https://www.wsj.com/articles/tomorrows-business-leaders-learn-how-to-work-with-ai-1480517287

The Guardian. Chatbot lawyer overturns 160,000 parking tickets in London and New York. Jun 2016. Disponível:

https://www.theguardian.com/technology/2016/jun/28/chatbot-ai-lawyer-donotpay-p arking-tickets-Iondon-new-york.

UNGER, Roberto Mangabeira. Depois do colonialismo mental: repensar e reorganizar o Brasil. Autonomia literária, 2018.

UNIÃO EUROPEIA. High-Level Expert Group on Artificial Intelligence. A definition of Artificial Intelligence: main capabilities and scientific disciplines (Uma definição de Inteligência Artificial: principais capacidades e disciplinas científicas). Abr 2019.

UNIÃO EUROPEIA. High-Level Expert Group on Artificial Intelligence. Ethics guidelines for trustworthy AI (Diretrizes éticas para uma inteligência artificial confiável). Abr 2019b. Disponível:

https://ec.europa.eu/diqital-single-market/en/news/ethics-quidelines-trustworthy-ai

FERRAZ, Fred. Jurimetria é ferramenta importante nas mãos de um bom advogado. Rev Conjur. Out 2018. Disponível:

https://www.conjur.com.br/2018-out-12/fred-ferraz-jurimetria-ferramenta-importante -direito

HEYMANN, Hanna Rocha. Direito e tecnologia: uma análise sobre a law tech. Escola da Magistratura do Estado do Rio de Janeiro. Rio de Janeiro, 2018.

NYBO, Erik. Como as lawtechs estão mudando a advocacia. E-commerce Brasil. Jul 2017. Disponível em:

https://www.ecommercebrasil.com.br/artigos/lawtechs-mudando-advocacia.

SILLS, Anthony. ROSS and Watson tackle the law. AI for Enterprise. IBM. Jan 2016. Disponível:

https://www.ibm.com/blogs/watson/2016/01/ross-and-watson-tackle-the-law/

ZIMMERMANN, Gustavo. Empresas Analitcs e Jurimetria. Lexnet. Jun 2018.

Disponível: http://www.lex-net.com/new/empresas-analitcs-e-jurimetria/ 